Copyright (c) Wolters Kluwer Health | Lippincott Williams \& Wilkins. Unauthorized reproduction of this article is prohibited.

J Head Trauma Rehabil

Copyright $\Subset 2012$ Wolters Kluwer Health | Lippincott Williams \& Wilkins

\title{
Decrease in $N$-Acetylaspartate Following Concussion May Be Coupled to Decrease in Creatine
}

\author{
Roberto Vagnozzi, MD; Stefano Signoretti, MD, PhD; Roberto Floris, MD; \\ Simone Marziali, MD; Massimo Manara, MD; Angela M. Amorini, PhD; \\ Antonio Belli, MD, PhD; Valentina Di Pietro, PhD; Serafina D'Urso, PhD; \\ Francesco S. Pastore, MD; Giuseppe Lazzarino, PhD; Barbara Tavazzi, PhD
}

Objectives: To assess the time course changes in $N$-acetylaspartate (NAA) and creatine (Cr) levels in the brain of athletes who suffered a sport-related concussion. Participants: Eleven nonconsecutive athletes with concussive head injury and 11 sex- and age-matched control volunteers Main outcome measures: At 3, 15, 30, and 45 days postinjury, athletes were examined by proton magnetic resonance spectroscopy for the determination of NAA, Cr, and choline (Cho) levels. Proton magnetic resonance spectroscopic data recorded for the control group were used for comparison. Results: Compared with controls $(2.18 \pm 0.19)$, athletes showed an increase in the NAA/Cr ratio at $3(2.71 \pm 0.16 ; P<.01)$ and $15(2.54 \pm 0.21 ; P<.01)$ days postconcussion, followed by a decrease and subsequent normalization at $30(1.95 \pm 0.16, P<.05)$ and $45(2.17 \pm 0.20 ; P<.05)$ days postconcussion. The NAA/Cho ratio decreased at 3,15 , and 30 days postinjury $(P<.01$ compared with controls), with no differences observed in controls at 45 days postconcussion. Compared with controls, significant increase in the Cho/Cr ratio after $3(+33 \%$, $P<.01)$ and $15(+31.5 \%, P<.01)$ days postinjury was observed whereas no differences were recorded at 30 and 45 days postinjury. Conclusions: This cohort of athletes indicates that concussion may cause concomitant decrease in cerebral NAA and Cr levels. This provokes longer time for normalization of metabolism, as well as longer time for resolution of concussion-associated clinical symptoms. Key words: brain vulnerability, concussion, creatine, ${ }^{1} \mathrm{H}$ magnetic resonance spectroscopy, mild traumatic brain injury, $\mathrm{N}$-acetylaspartate, sports-related concussion

Author Affiliations: Division of Neurotraumatology and Neuroradiology, Department of Biomedicine and Prevention, University of Rome "Tor Vergata," Rome, Italy (Drs Vagnozzi, Floris, Marziali, D'Urso, and Pastore); Division of Neurosurgery, Department of Neurosciences-Head and Neck Surgery, "San Camillo" Hospital, Rome, Italy (Dr Signoretti); Association of Sports Physicians Parma, F.M.S.I., Parma, Italy (Dr Manara); Institute of Biochemistry and Clinical Biochemistry, Catholic University of Rome, Rome, Italy (Drs Amorini and Tavazzi); Division of Biochemistry and Molecular Biology, Department of Biology, Geology and Environmental Sciences, University of Catania, Catania, Italy (Dr Lazzarino); and Neuropharmacology and Neurobiology Section, School of Clinical and Experimental Medicine, College of Medical and Dental Sciences and NIHR Surgical Reconstruction and Microbiology Research Centre, University of Birmingham and University Hospitals Birmingham, Birmingham, United Kingdom (Drs Belli and Di Pietro).

This work has been supported in part by research funds of University of Rome "Tor Vergata," Catholic University of Rome, and University of Catania. The authors thank Mr Salvatore Meo for his technical assistance in preparing the artwork for the manuscript.

The authors declare no conflicts of interest.

Correspondence: Giuseppe Lazzarino, PhD, Division of Biochemistry and Molecular Biology, Department of Biology, Geology and Environmental Sciences, Viale A. Doria 6, 95125 Catania, Italy (lazzarig@unict.it).

DOI: 10.1097/HTR.0b013e3182795045
ONCUSSION is defined as a biomechanically induced brain injury characterized by the absence of gross anatomic damages. Supported by the absence of structural lesions on traditional neuroimaging, a general and broadly accepted view is that mild traumatic brain injury (mTBI) is indeed a very frequent entity but is not a very serious injury, leading only to transient disturbances, and that no intervention other than observation is typically required. However, mTBI triggers molecular changes in neuronal cells involving a complex cascade of neurometabolic alterations $s^{1-3}$ that reversibly modify the concentrations of several low-molecular-weight compounds actively involved in functions crucial for cell homeostasis and survival. ${ }^{3,4}$ Such a cascade of molecular events is considered as the determinant of the so-called state of metabolic brain vulnerability, ${ }^{5,6}$ which transiently exposes cerebral tissue to the cumulative effect of a second mTBI occurring during this particular period. ${ }^{7,8}$ High-energy phosphates, ${ }^{9,10}$ coenzyme A metabolites, ${ }^{11}$ ATP catabolites, ${ }^{11}$ and neurotransmitters, ${ }^{12,13}$ are some of the substances whose concentrations are temporarily affected as a result of a traumatic insult. Of 
particular relevance is the finding that $N$-acetylaspartate (NAA), an abundant brain-specific compound involved in several relevant biological functions including water homeostasis ${ }^{14}$ and lipid myelin biosynthesis, ${ }^{15}$ clearly mirrors TBI-induced changes in ATP, showing the same pattern of decrease and recovery following $\mathrm{MTBI}$ and no recovery in severe TBI or repeat mTBIs. ${ }^{8,10,11}$ The strict correlation between NAA and ATP ensures that this compound may be used as a valid surrogate marker to monitor cerebral energy metabolism. ${ }^{8,10,11}$ Recently, particular attention has been given to compounds, noninvasively detectable in vivo by proton magnetic resonance (MR) spectroscopy $\left({ }^{1} \mathrm{H}\right.$ MRS), that may be used as markers of brain metabolism following mTBI. ${ }^{1} \mathrm{H}$ MRS allows the routine measurement of NAA, creatine $(\mathrm{Cr})$, and choline (Cho) in a single set of spectral acquisition, ${ }^{16}$ although the low magnetic field currently used in the clinical setting $(1.5$ or $3 \mathrm{~T})$ does not allow to resolve the $\mathrm{N}$-acetylaspartatylglutamate signal in the NAA peak ${ }^{17}$ or the creatine phosphate (CrP) signal in the $\mathrm{Cr}$ peak, ${ }^{17}$ or to resolve about 10 different compounds containing the choline moiety in their molecule in the Cho peak. ${ }^{17}$ NAA, Cr and Cho can be measured by ${ }^{1} \mathrm{H}$ MRS either by determining their absolute values ${ }^{17}$ or by using the metabolite ratios. ${ }^{18}$ When referring to NAA and $\mathrm{Cr}$, this is of limited relevance since, in the brain tissue, NAA and $\mathrm{Cr}$ are about 10 times more concentrated than their respective related compounds $\mathrm{N}$-acetylaspartatylglutamate and CrP. Therefore, areas of these 2 peaks can generally be considered as valid measurements of NAA and Cr levels. Differently, since the Cho peak is mainly composed of phosphocholine, glycerophosphocholine, and phosphatidylcholine, quantification of this peak area is not in direct correlation with one compound only. However, since these compounds are related to phospholipid metabolism, the Cho peak area is generally considered as a good indicator of the cell membrane turnover, ${ }^{17,19}$ that of NAA is used as a marker of energy state and neuronal integrity, ${ }^{8,10,11,17}$ and that of $\mathrm{Cr}$ is thought to be a marker of cellular energy. ${ }^{17}$

Since the period of brain vulnerability following an mTBI is mainly characterized by evident biochemical, metabolic, and molecular changes, $3,5,6,20$ it is questionable whether the tests currently adopted in the clinical practice to monitor mTBI patients (neuropsychological tests, balance tests, etc), because of their inability to evaluate cerebral biochemical changes, are of utility to determine the end of brain vulnerability. Although some of them (neuropsychological tests) are largely applied to assess the return of athletes with concussive head injury to play, ${ }^{21-23}$ it has never been demonstrated that this type of normalization overlaps with the recovery of brain metabolism.
In a constant effort to find valid objective biological parameters for the monitoring of brain metabolic recovery after head injury, several researchers, using ${ }^{1} \mathrm{H}$ MRS studies, turned their attention to the evaluation of the changes in NAA in mTBI patients. ${ }^{24,25}$ In two longitudinal studies in which patients were scanned 3 or 4 times to perform the time course of postinjury recovery of brain metabolism, we showed that concussion, an mTBI caused by any type of acceleration-deceleration of the brain, frequently encountered in contact sports, caused a reversible decrease in NAA content of the frontal lobe white matter. ${ }^{26,27}$ In these studies, an inclusion criterion was the constancy in the Cho/Cr ratio that allowed the semiquantitative determination of NAA relative to both $\mathrm{Cr}$ and Cho. ${ }^{26,27}$ Significantly, we observed that the recovery of brain metabolism occurred weeks after the resolution of the self-reported postconcussive clinical symptoms. ${ }^{26,27}$ Recently, two ${ }^{1} \mathrm{H}$ MRS studies reported that $\mathrm{Cr}$ but not NAA levels were affected by mTBI, with head injury producing a significant increase in $\mathrm{Cr}$ levels in different brain areas. ${ }^{28,29}$

As indicated earlier, in our previous studies, to investigate possible changes in NAA evaluated relatively to $\mathrm{Cr}$ and/or Cho, we excluded patients in whom the Cho/Cr ratio did not remain unaltered. In this article, we describe 11 cases of athletes with concussive head injury in whom alterations of brain metabolism involved not only NAA but Cr as well.

\section{METHODS}

\section{Patient selection}

After obtaining informed consent according to institutional procedures, 11 nonconsecutive amateur athletes of different sport disciplines who suffered a sport-related concussive head injury (defined as a traumatically induced alteration in mental status, not necessarily with loss of consciousness), between June 2008 and October 2011, were considered for this study. Patient selection was characterized by the following inclusion criteria: (i) Glasgow Coma Scale score 14 or more; (ii) no anatomic lesion at conventional imaging (computed tomography or magnetic resonance imaging [MRI]); (iii) normal neurological objective examination at the time of enrolment; (iv) the value of the $\mathrm{Cho} / \mathrm{Cr}$ ratio different from that of controls; and (v) the requirement to refrain from further athletic activity up to normalization of brain metabolism.

Athletes (age ranging between 16 and 35 years) underwent an MR scan and a proton spectroscopic examination at 3 days postinjury, followed by 3 additional ${ }^{1} \mathrm{H}$ MRS scans at 15, 30, and 45 days postinjury. Results collected from patients with concussive head injury were compared with those obtained from 11 healthy, sex-and 
Copyright (c) Wolters Kluwer Health | Lippincott Williams \& Wilkins. Unauthorized reproduction of this article is prohibited.

age-matched control volunteers, previously screened to exclude prior head injuries. Any intracranial lesion observed on the first MR scan automatically excluded the candidate from the study. Before each MR examination, symptoms were assessed by using the SCAT2, a tool that represents a standardized method of evaluating injured athletes for concussion and can be used in athletes aging 10 years and older. During the medical examination, patients were asked for symptoms of mTBI including physical, cognitive, emotional, and sleep disturbances. Resolution was determined by the concordance of the results of self-assessment and SCAT2.

\section{MRI and ${ }^{1} H$ MRS acquisition technique}

Semiquantitative analyses of $\mathrm{Cr}$, NAA, and Cho were performed after obtaining proton spectra by a 3-T system (Philips Intera Achieva, Philips Healthcare, Best, The Netherlands). For conventional MRI studies, T1and T2-weighted TSE (turbo spin-echo) images were acquired in axial, coronal, and sagittal planes, and to rule out even the smallest amount of intracerebral blood, fast field echo T2* sequences were used. A multichannel coil (8 channels) SENSE-Head-8, with 4-mm slice thickness, 1-mm gap, and an FOV (field of view) of $230 \mathrm{~mm}$, was used for all MRI sequences. Following localized shimming and water suppression, the spectroscopic examination was carried out using a PRESS (point resolved spectroscopy) pulse sequence, with the following settings: $\mathrm{TE}($ echo time $)=144 \mathrm{~ms}$; TR (repetition time $)=2000$ ms; spectral bandwidth $=2000$; and acquisition cycles $=128$. The optimal positioning of the voxel was determined using the MR images acquired on axial, coronal, and sagittal planes to facilitate its 3-dimensional placement, adjacent to the cortical-subcortical junction, just anterior to the frontal horn of the lateral ventricle, at the same height of a virtual plane positioned just above the corpus callosum, to include only the white matter of the frontal lobes bilaterally. The choice of this location was made to obtain as homogeneous data as possible. To this end, a spectrum from a single voxel customized to sample a volume of interest of $3.375 \mathrm{~cm}^{3}(1.5 \times 1.5 \times 1.5$ $\mathrm{cm}$ ) was finally obtained (acquisition time about $5 \mathrm{~min}$ utes for each voxel). In comparison with the multivoxel technique, the single-voxel technique was preferred to obtain a better resolution of the spectral peaks. In addition, in our previous article, data obtained from different neuroradiological centers and using the single- or multivoxel technique gave overlapping values. ${ }^{27}$ In follow-up studies, the exact repositioning of the voxel on the same acquisition plane obtained in the previous MRI study was achieved by using dedicated software (SameScan; Philips Medical Systems, Philips Healthcare, Best, The Netherlands). Postprocessing of spectral data allowed us to calculate the area under the peaks of NAA, Cho, and
$\mathrm{Cr}$, using common criteria for peak integration. In the case of a single, well-defined peak (typically the NAA peak), a valley-to-valley integration was performed to obtain the area under the peaks. In the case of not fully resolved peaks (frequently the Cho and Cr peaks), a horizontal baseline between the start of the first peak and the end of the second peak was selected; the grouped peaks were then split by a vertical line, drawn from the median point of the common valley between peaks to the horizontal baseline and the area under the peaks calculated. These values were used to determine the metabolite ratios NAA/Cho, NAA/Cr, and Cho/Cr.

\section{Statistical analysis}

All data analyses and calculations of sample size were performed using the Statistical Package for the Social Sciences Windows version 13.0 (SPSS, Chicago, Illinois). Descriptive statistics for quantitative continuous variables were presented as mean \pm standard deviation. Assumptions of normality were demonstrated using the Kolmogorov-Smirnov test. The homogeneity of the variance was evaluated with the Levene test. Analysis of variance for repeated measures, corrected by Bonferroni, was used to evaluate significant differences among groups. Differences were considered to be statistically significant when $P<.05$.

\section{RESULTS}

\section{Clinical features of athletes with concussive head injury}

A total of 55 single-voxel ${ }^{1} \mathrm{H}$ MRS studies (11 healthy control subjects, 11 patients studied at 4 time points) were conducted, and a total of 110 brain spectra were successfully acquired. The duration of each study averaged $16 \pm 1$ minute, with no complications reported. All patients were admitted as outpatients and discharged within 1 hour from the beginning of the MRI and ${ }^{1} \mathrm{H}$ MRS acquisitions. The clinical features of the cohort of athletes with concussive head injury are reported in Table 1 . The mean age of athletes with concussive head injury was $24.6 \pm 6.4$ years ( 8 men, 3 women) and that of controls was $25.9 \pm 5.7$ years ( 8 men, 3 women). A complete resolution of symptoms, obtained when the concordance of the results of self-assessment and SCAT2 occurred, was observed at $15.2 \pm 2.6$ days postinjury.

\section{${ }^{1} \mathrm{H}$ MRS analysis of brain metabolism in patients with concussive head injury}

Figure 1 shows the optimal positioning of the voxel and a spectrum recorded in a healthy control subject. The time course of the NAA/Cr ratio determined in 11 patients with head injury at different time points following concussion is illustrated in Figure 2. Different 
TABLE 1 Demographic data, sport activity, mechanisms of concussion, and clinical symptoms of 11 nonprofessional athletes with concussive head injury

\begin{tabular}{|c|c|c|c|c|c|c|}
\hline Case & Age, y & Sex & Sport practiced & $\begin{array}{l}\text { Mechanisms of } \\
\text { concussion }\end{array}$ & Symptoms & $\begin{array}{l}\text { Duration of } \\
\text { symptoms, } d\end{array}$ \\
\hline 1 & 23 & $\mathrm{M}$ & Soccer & $\begin{array}{l}\text { Elbow-to-head } \\
\text { impact }\end{array}$ & $\begin{array}{l}\text { Headache, difficulty in } \\
\text { concentrating, } \\
\text { irritability }\end{array}$ & 14 \\
\hline 2 & 35 & M & Soccer & Knee-to-head impact & $\begin{array}{l}\text { Headache, nausea, } \\
\text { retrograde amnesia }\end{array}$ & 12 \\
\hline 3 & 29 & $\mathrm{~F}$ & Alpine skiing & $\begin{array}{l}\text { Contra-coup injury } \\
\text { caused by low } \\
\text { back impact }\end{array}$ & $\begin{array}{l}\text { Headache, sleep } \\
\text { disturbances, feeling } \\
\text { "foggy" }\end{array}$ & 19 \\
\hline 4 & 17 & M & Soccer & Foot-to-head impact & $\begin{array}{l}\text { Headache, sleep } \\
\text { disturbances }\end{array}$ & 16 \\
\hline 5 & 19 & M & Soccer & Head-to-head impact & $\begin{array}{l}\text { Headache, retrograde } \\
\text { amnesia }\end{array}$ & 17 \\
\hline 6 & 30 & M & Boxing (amateur) & Punch-to-chin impact & $\begin{array}{l}\text { Headache, anterograde } \\
\text { amnesia, sleep } \\
\text { disturbances }\end{array}$ & 13 \\
\hline 7 & 22 & $\mathrm{~F}$ & Basketball & $\begin{array}{l}\text { Elbow-to-head } \\
\text { impact }\end{array}$ & $\begin{array}{l}\text { Headache, fatigue, } \\
\text { nervousness }\end{array}$ & 14 \\
\hline 8 & 28 & M & Boxing & Punch to face impact & Headache, irritability & 18 \\
\hline 9 & 20 & M & Rugby & Head to trunk impact & $\begin{array}{l}\text { Headache, retrograde } \\
\text { amnesia }\end{array}$ & 15 \\
\hline 10 & 18 & $F$ & $\begin{array}{l}\text { Kick boxing (light } \\
\text { contact) }\end{array}$ & Foot-to-head impact & $\begin{array}{l}\text { Headache, difficulty in } \\
\text { concentrating }\end{array}$ & 18 \\
\hline 11 & 27 & M & Boxing (amateur) & Punch-to-chin impact & $\begin{array}{l}\text { Headache, sleep } \\
\text { disturbances }\end{array}$ & 11 \\
\hline
\end{tabular}

from what was previously obtained in patients sustaining similar types of concussion and showing similar clinical conditions, ${ }^{26,27}$ at the time of the first ${ }^{1} \mathrm{H}$ MRS scan (3 days postimpact), we recorded a significant increase in the NAA/Cr ratio $(2.71 \pm 0.16)$ with respect to the value of controls $(2.18 \pm 0.19 ; P<.01)$. This apparent NAA increase was also evidenced 15 days after injury, when the 11 athletes with concussive head injury showed the $\mathrm{NAA} / \mathrm{Cr}$ ratio of $2.54 \pm 0.21(+16.5 \% ; P<.01$ with respect to the value of controls). Unexpectedly, at the time of the third ${ }^{1} \mathrm{H}$ MRS scan (30 days postconcussion), significant decrease in the NAA/Cr ratio was observed $(1.95 \pm 0.16, P<.05$ with respect to controls). A value of $2.17 \pm 0.2$, not significantly different from that recorded in controls, was measured 45 days after concussion.

Figure 3 illustrates the changes in the NAA/Cho ratio during 45 days following concussion. In accordance with our previous observations, ${ }^{26,27}$ but in contrast to the apparent increase in NAA suggested by the increase in the NAA/Cr ratio, the NAA/Cho ratio underwent a transient decrease, particularly evident at 3 and 15 days postinjury when mean values of $1.61 \pm 0.20$ and 1.55 \pm 0.18 were recorded (mean value of the NAA/Cho ratio in controls $=1.94 \pm 0.17 ; P<.01)$. At the time of the third ${ }^{1} \mathrm{H}$ MRS scan, the NAA/Cho ratio slightly increased $(1.70 \pm 0.2)$, although this was still $12.4 \%$ lower than that in controls $(P<.01)$. Recovery of the NAA/Cho ratio was completed 45 days postconcussion when a value of $1.91 \pm 0.19$ was recorded (not significantly different from controls).

Data reported in Figure 4 show the changes in the $\mathrm{Cho} / \mathrm{Cr}$ ratio observed in 11 athletes with concussive head injury during 45 days of recovery. Different from what was observed in our previous studies, in which the $\mathrm{Cho/Cr}$ ratio remained unaltered during the whole observational period after concussion, ${ }^{26,27}$ in the present cohort of athletes, we observed a significant increase in the Cho/Cr ratio after $3(+33 \% ; P<.01)$ and 15 $(+31.5 \% ; P<.01)$ days postinjury. At the third and fourth ${ }^{1} \mathrm{H}$ MRS scans (30 and 45 days postimpact, respectively), no difference in the $\mathrm{Cho/Cr}$ ratio was observed compared with controls.

To illustrate more clearly the postinjury phenomenon involving a decrease in NAA and Cr levels and constancy of Cho in this cohort of athletes, Figure 5 shows ${ }^{1} \mathrm{H}$ MR spectra both of a representative control and of a concussed athlete analyzed at 3,30 , and 45 days postinjury (for graphical reasons, the 15-day spectrum was not reported). A visible decrease in the NAA and Cr peaks at 3 days, with subsequent increase and normalization at 30 and 45 days postconcussion, is evident. Differently, the Cho peak did not show appreciable modifications 

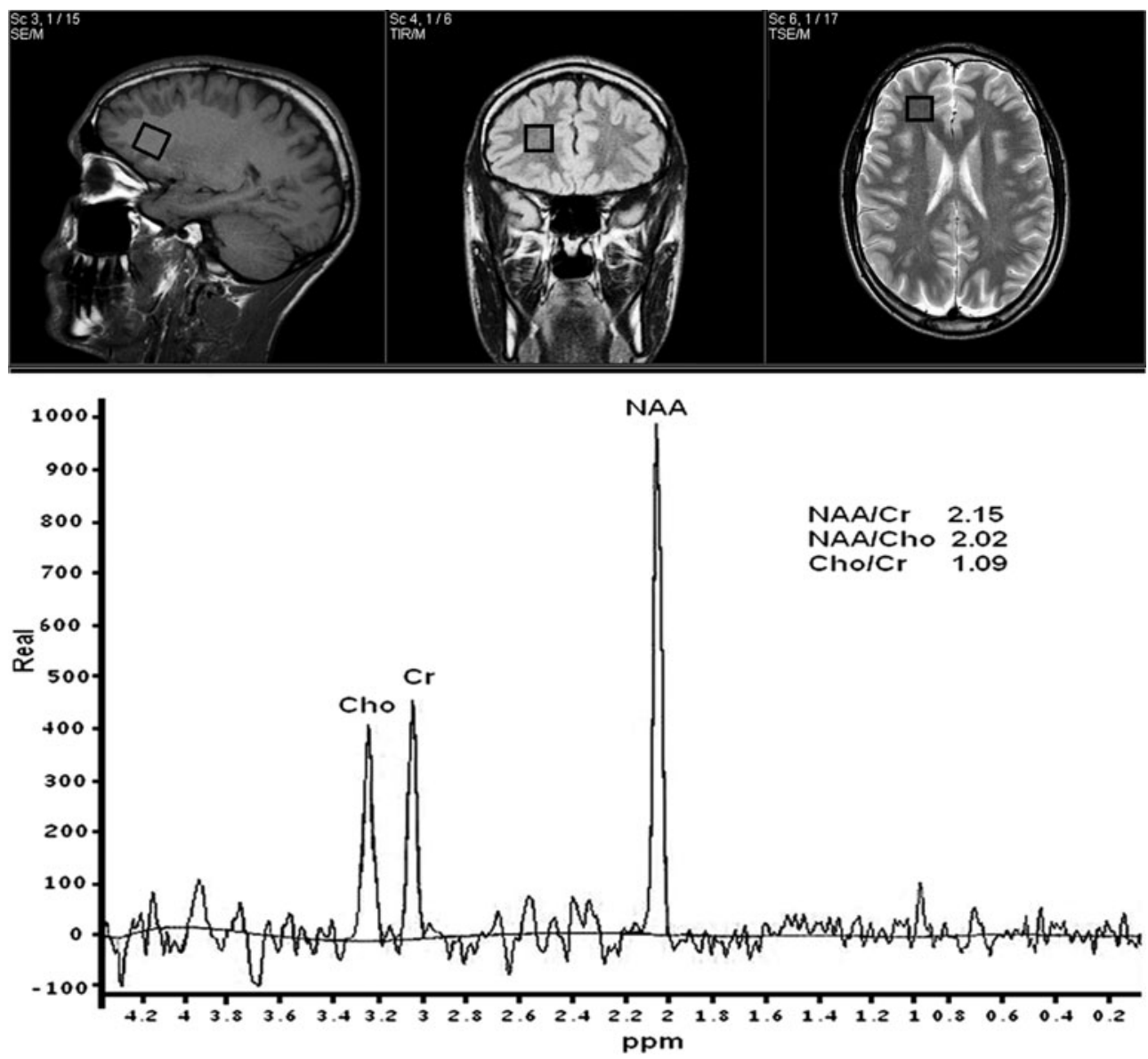

Figure 1. ${ }^{1} \mathrm{H}$ magnetic resonance scout image of a healthy volunteer showing the optimal positioning of the single voxel located adjacent to the cortical-subcortical junction, just anteriorly to the frontal horn of the lateral ventricle, at the same height of a virtual plane positioned just above the corpus callosum, to include only the white matter of the frontal lobes, bilaterally. The proton spectrum shows the peaks corresponding to the metabolites of interest $N$-acetylaspartate (NAA), creatine (Cr), and choline (Cho). The calculated NAA/Cr and $\mathrm{Cho} / \mathrm{Cr}$ ratios, relative to this subject, are also indicated.

at any time point, being very similar to that recorded in the control healthy subject (Figure 5).

\section{DISCUSSION}

We previously showed that athletes with concussive head injury experience a period of metabolic brain derangement, as evidenced by the transient decrease in the NAA/Cr and NAA/Cho ratios. ${ }^{26,27}$ In both studies, one of the criteria for inclusion was the constancy of the Cho/Cr ratio since, for the calculation of the relative NAA abundance, it is always necessary to refer to an invariant metabolite detectable in the ${ }^{1} \mathrm{H}$ MR spectrum. In these studies, the trends in the NAA/Cr and NAA/Cho ratios after a concussive episode entirely overlapped, thereby supporting the conclusion that $\mathrm{Cr}$ and Cho concentrations did not vary (as indicated by the constancy in the $\mathrm{Cho} / \mathrm{Cr}$ ratio) and that the changes in the NAA/Cr and NAA/Cho ratios were due to a real net decrease in NAA cerebral concentration, ${ }^{26,27}$ that is, the NAA decrease was merely apparent.

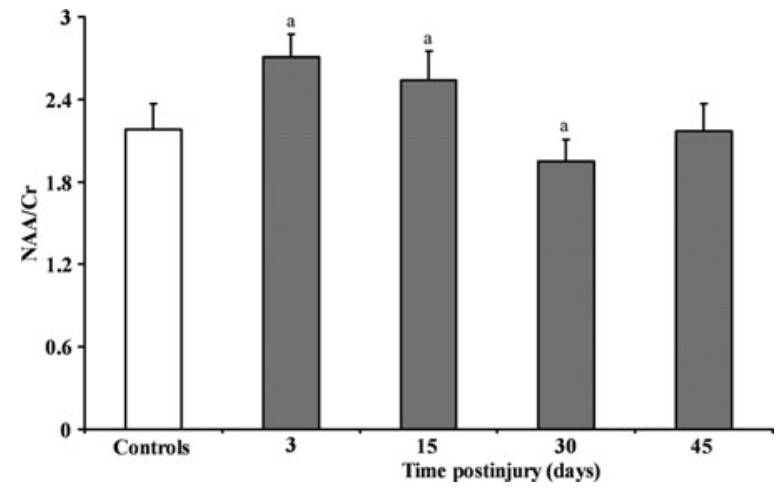

Figure 2. Bar graph showing the metabolite ratios of $\mathrm{N}$-acetylaspartate/creatine-containing compounds (NAA/Cr) in controls and patients with concussive head injury. Each bar is the mean value determined in 11 healthy controls and 11 athletes with concussive head injury. Standard deviations are represented by vertical bars. At 3 and 15 days, the NAA/Cr ratio increased by $24.3 \%$ and $16.5 \%$, respectively, whereas at 30 days postinjury, it decreased by $10.6 \%$. Normalization was observed 45 days after concussion. ${ }^{\text {a }} P<.05$ with respect to controls. 
Copyright (c) Wolters Kluwer Health | Lippincott Williams \& Wilkins. Unauthorized reproduction of this article is prohibited.

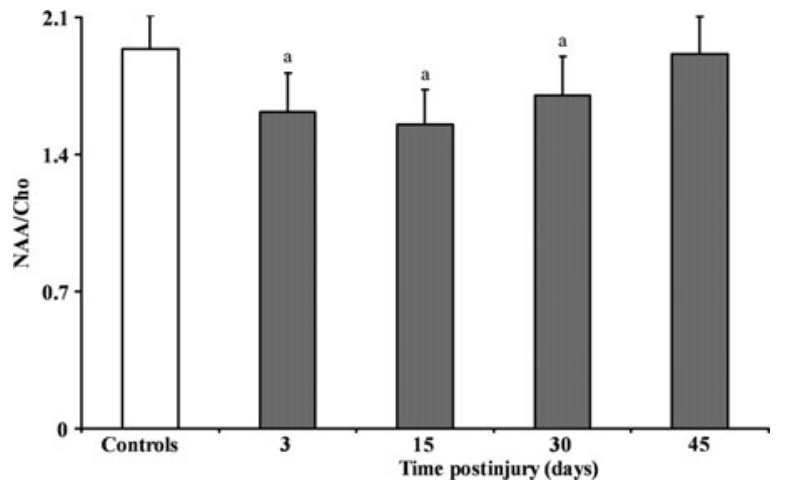

Figure 3. Bar graph showing the metabolite ratios of $N$-acetylaspartate/choline-containing compounds (NAA/Cho) in controls and patients with concussive head injury. Each bar is the mean value determined in 11 healthy controls and 11 athletes with concussive head injury. Standard deviations are represented by vertical bars. At 3, 15 , and 30 days postinjury the NAA/Cho ratio decreased by $17.0 \%, 20.1 \%$, and $12.4 \%$, respectively. Normalization was observed 45 days after concussion. ${ }^{a} P<.05$ with respect to controls.

In this study, we found a profound discrepancy between the trends of the NAA/Cr (transient increase and then decrease before normalization) and NAA/Cho (transient decrease) ratios. The incongruity in the trends of these 2 metabolite ratios was accompanied by a temporary increase in the $\mathrm{Cho} / \mathrm{Cr}$ ratio, significantly higher than the value in age-matched healthy controls at 3 and 15 days postinjury, and then normalized 30 days after concussion (Figure 3). According to the aforementioned observations, it can be affirmed that in these athletes, the following observations were made: (i) the fluctuating NAA/Cr ratio (Figure 1) was due to a decrease in NAA

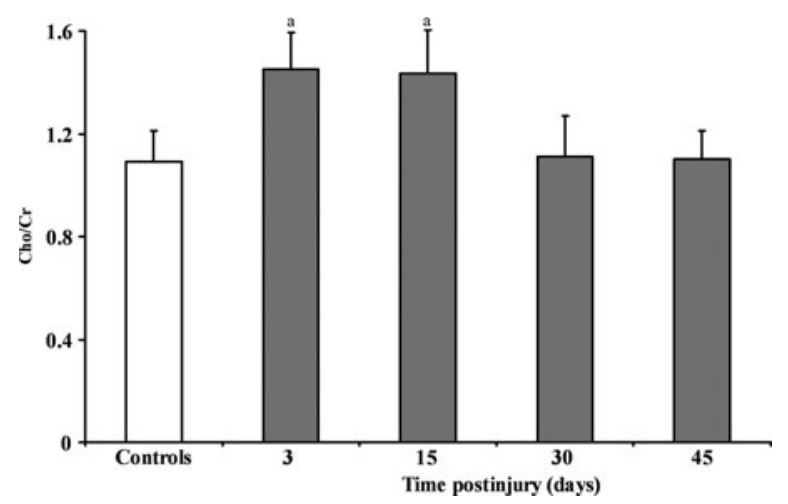

Figure 4. Bar graph showing the metabolite ratios of choline/creatine-containing compounds $(\mathrm{Cho} / \mathrm{Cr})$ in controls and patients with concussive head injury. Each bar is the mean value determined in 11 healthy controls and 11 athletes with concussive head injury. Standard deviations are represented by vertical bars. At 3 and 15 days, the $\mathrm{Cho} / \mathrm{Cr}$ ratio increased by $33.0 \%$ and $31.5 \%$, respectively, whereas at 30 and 45 days postinjury, no differences with respect to controls were recorded. ${ }^{\text {a }} P<.05$ with respect to controls. and a concomitant, more pronounced decrease in $\mathrm{Cr}$ levels; (ii) the decrease in the NAA/Cho ratio (Figure 2) was due to a significant decrease in NAA and not due to an increase in Cho levels; (iii) the increase in the Cho/Cr ratio was due to a decrease in Cr levels (Figure 3); (iv) the recovery of Cr was faster than that of NAA, as evidenced by normalization in the $\mathrm{Cho} / \mathrm{Cr}$ ratio recorded 30 days postconcussion whereas the NAA/Cr ratio was still decreased (Figure 1 and 3). To corroborate these conclusions that clearly explained the apparently contradictory trends of the metabolite ratios, in each athlete, the area under the peak of the spectral signal of Cho did not change at any of the different ${ }^{1} \mathrm{H}$ MRS acquisitions and was similar to that recorded in controls (data not shown). Conversely, the area under the peak of NAA was lower at 3, 15, and 30 days postinjury and that of $\mathrm{Cr}$ at 3 and 15 days after impact (data not shown). Even if referred to one representative athlete only, this phenomenon is clearly visible in the spectra reported in Figure 5, which show a decrease and subsequent normalization in the NAA and Cr peaks and no change in the peak of Cho.

One question that can be raised from these results is why these athletes showed a transient decrease in both $\mathrm{Cr}$ and NAA levels whereas the other 40 we examined in 2 previous studies ${ }^{26,27}$ showed decrease in NAA levels only, with no change in Cr levels. It should be noted that athletes enrolled in the present study differ not only in decrease in Cr levels but also in the longer time necessary for NAA normalization (45 days vs 30 days observed previously), as well as for the longer duration of the postconcussive clinical symptoms $(15.2 \pm 2.6$ days vs 3-7 or 3-15 days recorded previously). Therefore, it appears that this group of athletes suffered from a more severe concussive event, causing longer time in both clinical and metabolic recovery and a more pronounced imbalance of metabolism (change in both NAA and Cr concentrations). On the other hand, using the weightdrop model of closed-head diffuse $\mathrm{mTBI},{ }^{30}$ we recently demonstrated that, in addition to NAA and ATP, Cr levels underwent a reversible $44.5 \%$ decline, which was accompanied by a less than $15 \%$ decline in CrP levels at the same time point ( 24 hours post-mTBI). Altogether, the sum of $\mathrm{Cr}+\mathrm{CrP}$ accounted for a $42 \%$ decrease at 24 hours postinjury. ${ }^{31}$ This transient depletion in the cerebral Cr compound pool was restored after 120 hours of mTBI. ${ }^{31}$ In the same study, we also showed that mTBI did not affect the concentration of phosphatidylcholine, that is, one of the main compounds responsible for the intensity signal of the Cho peak in the ${ }^{1} \mathrm{H}$ MR spectrum. These experimental results have recently been confirmed ${ }^{32}$ and strongly corroborate the finding reported in the present study, indicating temporary decrease in NAA and Cr levels and no change in Cho levels in our cohort of athletes with postconcussive head injury. 
Copyright (c) Wolters Kluwer Health | Lippincott Williams \& Wilkins. Unauthorized reproduction of this article is prohibited.

Concomitant Decrease in N-Acetylaspartate and Creatine Postconcussion
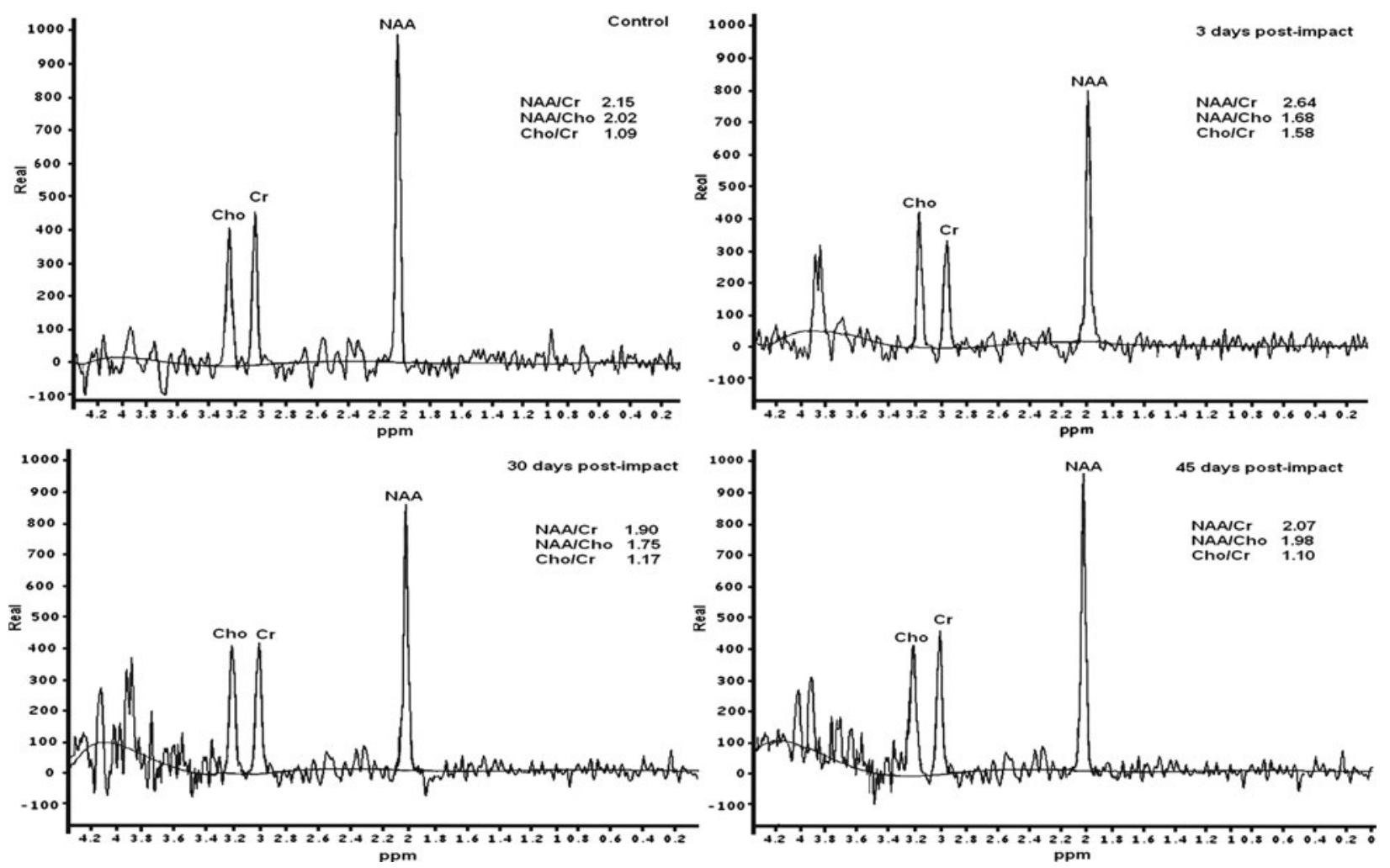

Figure 5. Representative ${ }^{1} \mathrm{H}$ magnetic resonance spectra recorded in a healthy control subject and in a concussed athlete at 3 , 30, and 45 days postinjury (for graphical reasons, the 15-day spectrum was not reported). Decrease (3 days), recovery (30 days), and subsequent normalization (45 days) in the NAA and Cr peaks and no change in the peak of Cho are clearly visible in the spectra of the postconcussed athlete.

Other authors indicated that patients suffering from mTBI underwent transient increase in Cr levels in the white matter and no change in NAA levels, ${ }^{28,29}$ in contrast to the results of the present and previous studies ${ }^{16,26,27,33,34}$ and also to a conspicuous number of preclinical studies demonstrating temporary decrease in $\mathrm{NAA}^{8,10,11,21}$ and $\mathrm{Cr}$ pool following mTBI. ${ }^{31,32}$ To explain their results, these authors concluded that an increase in total $\mathrm{Cr}(\mathrm{Cr}$ and $\mathrm{CrP})$ levels in the white matter may support a larger pool of high-energy phosphates ( $\mathrm{CrP}$ and ATP), helping to restore mTBI-induced alteration of cell homeostasis through upregulation of membrane pumps and other processes of cellular repair. ${ }^{28,29}$ Notwithstanding, these conclusions are in contrast with the notion of brain vulnerability, ${ }^{1-3,5-8,10,11,35}$ which is characterized by a period of metabolic depression (hypometabolism), mainly due to mitochondrial malfunctioning, ${ }^{36-38}$ particularly affecting NAA homeostasis ${ }^{39}$ and ATP supply, ${ }^{8-11,31,39}$ and also causing significant depletion in the total $\mathrm{Cr}$ pool. ${ }^{31,32}$ Furthermore, given the relative $\mathrm{CrP} / \mathrm{ATP}$ ratio in the brain tissue, ranging from about 0.8 (from Bryant et al) 32 to about 0.33 (from Signoretti et al), ${ }^{31}$ it seems implausible that $\mathrm{CrP}$ may efficiently buffer ATP stores in the case of impaired ATP homeostasis. In tissues in which the $\mathrm{Cr}-\mathrm{CrP}$ system has the specific role to buffer the rapid ATP decrease caused by sudden increase in the high-energy demand, such as the muscle or cardiac tissues, the CrP/ATP ratio ranges from 34 (in muscles) to 1.2-1.5 (in the myocardium). Recent data seem to indicate that the $\mathrm{Cr}$-CrP system in the brain plays an important role in performing the translocation of newly synthesized ATP from the mitochondrial compartment to the cytoplasmic compartment ${ }^{40}$ and that $\mathrm{Cr}$ may act as a neurotransmitter. ${ }^{40,41}$ Therefore, the postulated increase in total Cr levels following mTBI reported elsewhere ${ }^{28,29}$ does not seem to have the support of either preclinical ${ }^{31,32}$ or clinical studies, ${ }^{26,27,33,34}$ or have a valid biochemical explanation. Conversely, the decrease in total $\mathrm{Cr}$ levels observed in our group of athletes with concussive head injury may well be explained by the experimentally documented general depression of brain metabolism after $\mathrm{mTBI}$ and corresponding to the window of metabolic brain vulnerability. Since $\mathrm{Cr}$ homeostasis in the brain is regulated by exogenous $\mathrm{Cr}$ source as well as de novo intracellular synthesis, imbalance in cerebral Cr levels might be caused either by a decreased activity of the $\mathrm{Cr}$ transporter ${ }^{40,42}$ or by an inhibition of the $\mathrm{Cr}$ synthesis. ${ }^{40,42-44}$ 
Copyright (c) Wolters Kluwer Health | Lippincott Williams \& Wilkins. Unauthorized reproduction of this article is prohibited.

A further consideration about this intricate matter of the $\mathrm{Cr}$ levels following $\mathrm{mTBI}^{26-29}$ is given by the preliminary evidence that dietary supplementation of $\mathrm{Cr}$ can facilitate recovery of function in TBI. ${ }^{45-47}$ If cerebral Cr levels were induced to increase following mTBI, it is not clear why exogenously administered $\mathrm{Cr}$ would enhance recovery after TBI. On the contrary, positive effects of $\mathrm{Cr}$ administration would easily be explained by the notion that TBI is responsible for a decrease (not an increase) in cerebral $\mathrm{Cr}$ concentrations and that the exogenous $\mathrm{Cr}$ administration may reduce $\mathrm{Cr}$ depletion caused by TBI.

Different from those of previous studies, ${ }^{28,29}$ our results have been obtained by performing repeated ${ }^{1} \mathrm{H}$ MRS measures on each athlete (4 per athlete), up to normalization of brain metabolism related to energy supply and mitochondrial functioning. Therefore, as previously reported, ${ }^{26,27}$ the present research offers a real time course of NAA, Cr, and Cho following mTBI, demonstrating transient cerebral hypometabolism (decrease in NAA and $\mathrm{Cr}$ ) corresponding to the window of metabolic brain vulnerability. ${ }^{1-3,5-8,10,11,35}$ In light of the data questioning the validity of neuropsychological tests to determine the safe return of athletes to play, ${ }^{48,49}$ the present results, besides confirming that recovery of brain metabolism occurs much later than disappearance of postconcussive symptoms, once again indicate that ${ }^{1} \mathrm{H}$ MRS is a potent, unique tool with which to monitor the closure of the window of metabolic brain vulnerability following mTBI that may involve important brain metabolites such as NAA and Cr. Furthermore, the very recent report carried out in a cohort of 24 symptomfree athletes with concussive head injury (as assessed by clinical self-reported symptom resolution, cognitive and clinical balance testing (SCAT2 and Balance Error Scoring System), and clearance from a medical professional for the first stage of aerobic activity) showing significant alterations in brain metabolism (decrease in NAA in the genu but not in the splenium of the corpus callosum) strongly support the concept that clinical resolution is not coincident with normalization of brain metabolism. ${ }^{50}$

Therefore, the use of ${ }^{1} \mathrm{H}$ MRS in athletes affected by sports-related concussions is highly recommended to evaluate recovery of their cerebral metabolism. Until now, resolution of clinical symptoms has been used as the basis for returning to sports after a concussion. Given the findings of this study, we wonder what a physician, physiotherapist, or trainer would tell a concussed athlete to "go back on the field" after clinical resolution of symptoms, knowing that this athlete still has an abnormal ${ }^{1} \mathrm{H}$ MRS result that signifies a cerebral metabolism marker that has not yet fully recovered. Nevertheless, an important empirical question needing further investigation is whether the sensitivity and specificity of metabolic indices described in this article will provide better risk prediction of a more severe concussion the next time a concussion occurs. Future studies might also help to understand whether different brain areas undergo to metabolic changes similar to those we constantly found by placing voxel in the subcortical region of the frontal lobe.

\section{REFERENCES}

1. Giza CC, Hovda DA. The neurometabolic cascade of concussion. J Atbl Train. 2001;36:228-235.

2. Barkhoudarian G, Hovda DA, Giza CC. The molecular pathophysiology of concussive brain injury. Clin Sports Med. 2011;30:33-48.

3. Signoretti S, Vagnozzi R, Tavazzi B, Lazzarino G. Biochemical and neurochemical sequelae following mild traumatic brain injury: summary of experimental data and clinical implications. Neurosurg Focus. 2010;29:E1-E12.

4. Tweedie D, Milman A, Holloway HW, et al. Apoptotic and behavioral sequelae of mild brain trauma in mice. $J$ Neurosci Res. 2007;85:805-815.

5. Hovda DA, Badie H, Karimi S, et al. Concussive brain injury produces a state of vulnerability for intracranial pressure perturbation in the absence of morphological damage. In: Avezaat CJJ, van Eijndhoven JHM, Maas AIR, Tans JTJ, eds. Intracranial Pressure VIII. New York, NY: Springer-Verlag; 1983:469-472.

6. Hovda DA, Prins M, Becker DP, Lee S, Bergsneider M, Martin NA. Neurobiology of concussion. In: Bailes JE, Lovell MR, Maroon JC, eds. Sports Related Concussion. St Louis, MO: Quality Medical Publishing Inc; 1999:12-51.

7. Laurer HL, Bareyre FM, Lee VM, et al. Mild head injury increasing the brain's vulnerability to a second concussive impact. J Neurosurg. 2001;95:859-870.
8. Vagnozzi R, Signoretti S, Tavazzi B, et al. Hypothesis of the postconcussive vulnerable brain: experimental evidence of its metabolic occurrence. Neurosurgery. 2005;57:164171.

9. Arun P, Ariyannur PS, Moffett JR, et al. Metabolic acetate therapy for the treatment of traumatic brain injury. J Neurotrauma. 2010;27:293-298.

10. Tavazzi B, Signoretti S, Lazzarino G, et al. Cerebral oxidative stress and depression of energy metabolism correlate with severity of diffuse brain injury in rats. Neurosurgery. 2005;56:582-589.

11. Vagnozzi R, Tavazzi B, Signoretti $S$, et al. Temporal window of metabolic brain vulnerability to concussions: mitochondrialrelated impairment, part I. Neurosurgery. 2007;61:379389.

12. Faden AI, Demediuk P, Panter SS, Vink R. The role of excitatory amino acids and NMDA receptors in traumatic brain injury. Science. 1989;244:798-800.

13. Katayama Y, Becker DP, Tamura T, Hovda DA. Massive increases in extracellular potassium and the indiscriminate release of glutamate following concussive brain injury. J Neurosurg. 1990;73:889900 .

14. Baslow $\mathrm{MH}$. Brain $N$-acetylaspartate as a molecular water pump and its role in the etiology of Canavan disease: a mechanistic explanation. J Mol Neurosci. 2003;21:185-190. 


\section{Copyright (c) Wolters Kluwer Health | Lippincott Williams \& Wilkins. Unauthorized reproduction of this article is prohibited.}

15. Arun P, Madhavarao CN, Moffett JR, et al. Metabolic acetate therapy improves phenotype in the tremor rat model of Canavan disease. J Inherit Metab Dis. 2010;33:195-210.

16. Gruber S, Pinker K, Riederer F, et al. Metabolic changes in the normal ageing brain: consistent findings from short and long echo time proton spectroscopy. Eur J Radiol. 2008;68:320-327.

17. Rigotti DJ, Inglese $\mathrm{M}$, Gonen $\mathrm{O}$. Whole-brain $N$-acetylaspartate as a surrogate marker of neuronal damage in diffuse neurologic disorders. AJNR Am J Neuroradiol. 2007;28:1843-1849.

18. Garnett MR, Blamire AM, Corkill RG, Cadoux-Hudson TA, Rajagopalan B, Styles P. Early proton magnetic resonance spectroscopy in normal-appearing brain correlates with outcome in patients following traumatic brain injury. Brain 2000;123:20462054.

19. Senaratne R, Milne AM, MacQueen GM, Hall GB. Increased choline-containing compounds in the orbitofrontal cortex and hippocampus in euthymic patients with bipolar disorder: a proton magnetic resonance spectroscopy study. Psychiatry Res. 2009;172:205-209.

20. Yoshino A, Hovda DA, Kawamata T, Becker DP. Dynamic changes in local cerebral glucose utilization following cerebral concussion in rats: evidence of a hyper and subsequent hypometabolic state. Brain Res. 1991;561:106-119.

21. McCrea M, Guskiewicz KM, Marshall SW, et al. Acute effects and recovery time following concussion in collegiate football players: the NCAA Concussion Study. JAMA. 2003;290:2556-2563.

22. Randolph C, Millis S, Barr WB, et al. Concussion symptom inventory: an empirically derived scale for monitoring resolution of symptoms following sport-related concussion. Arch Clin Neuropsychol. 2009;24:219-229.

23. Schatz P, Pardini JE, Lovell MR, Collins MW, Podell K. Sensitivity and specificity of the ImPACT Test Battery for concussion in athletes. Arch Clin Neuropsychol. 2006;21:91-99.

24. Lin AP, Liao HJ, Merugumala SK, Prabhu SP, Meehan WP III, Ross BD. Metabolic imaging of mild traumatic brain injury. Brain Imaging Behav. 2012;6:208-223.

25. Difiori JP, Giza CC. New techniques in concussion imaging. Curr Sports Med Rep. 2010;9:35-39.

26. Vagnozzi R, Signoretti S, Tavazzi B, et al. Temporal window of metabolic brain vulnerability to concussion: a pilot ${ }^{1} \mathrm{H}$-magnetic resonance spectroscopic study in concussed athletes, part III. Neurosurgery. 2008;62:1286-1295.

27. Vagnozzi R, Signoretti S, Cristofori L, et al. Assessment of metabolic brain damage and recovery following mild traumatic brain injury: a multicentre, proton magnetic resonance spectroscopic study in concussed patients. Brain. 2010;133:3232-3242.

28. Gasparovic C, Yeo R, Mannell M. Neurometabolite concentrations in gray and white matter in mild traumatic brain injury: an ${ }^{1} \mathrm{H}$-magnetic resonance spectroscopy study. J Neurotrauma. 2009;26:1635-1643.

29. Yeo RA, Gasparovic C, Merideth F, Ruhl D, Doezema D, Mayer AR. A longitudinal proton magnetic resonance spectroscopy study of mild traumatic brain injury. J Neurotrauma. 2011;28:1-11.

30. Marmarou A, Foda MA, van den Brink W, Campbell J, Kita H, Demetriadou K. A new model of diffuse brain injury in rats, part I: pathophysiology and biomechanics. J Neurosurg. 1994;80:291300 .

31. Signoretti S, Di Pietro V, Vagnozzi R, et al. Transient alterations of creatine, creatine phosphate, $N$-acetylaspartate and high-energy phosphates after mild traumatic brain injury in the rat. Mol Cell Biochem. 2010;333:269-277.

32. Bryant YD, Prins ML, Hovda DA, Harris NG. Ketogenic diet prevents alterations in brain metabolism in young but not adult rats after traumatic brain injury. J Neurotrauma. 2011;28:18131825.
33. Govindaraju V, Gauger G, Manley G, Ebel A, Meeker M, Maudsley AA. Volumetric proton spectroscopic imaging of mild traumatic brain injury. AJNR Am J Neuroradiol. 2004;25:730737.

34. Govind V, Gold S, Kaliannan K, et al. Whole-brain proton MR spectroscopic imaging of mild-to moderate traumatic brain injury and correlation with neuropsychological deficits. J Neurotrauma. 2010;27:483-496.

35. Longhi L, Saatman KE, Fujimoto $S$, et al. Temporal window of vulnerability to repetitive experimental concussive brain injury. Neurosurgery. 2005;56:354-374.

36. Darwish RS, Amiridze NS. Detectable levels of cytochrome $c$ and activated caspase-9 in cerebrospinal fluid after human traumatic brain injury. Neurocrit Care. 2010;12:337-341.

37. Kilbaugh TJ, Bhandare S, Lorom DH, Saraswati M, Robertson CL, Margulies SS. Cyclosporin A preserves mitochondrial function after traumatic brain injury in the immature rat and piglet. $J$ Neurotrauma. 2011;28:763-774.

38. Sauerbeck A, Gao J, Readnower R, et al. Pioglitazone attenuates mitochondrial dysfunction, cognitive impairment, cortical tissue loss, and inflammation following traumatic brain injury. Exp Neurol. 2011;227:128-135.

39. Signoretti S, Marmarou A, Tavazzi B, Lazzarino G, Beaumont A, Vagnozzi R. N-Acetylaspartate reduction as a measure of injury severity and mitochondrial dysfunction following diffuse traumatic brain injury. J Neurotrauma. 2001;18:977991.

40. Beard E, Braissant O. Synthesis and transport of creatine in the CNS: importance for cerebral functions. $J$ Neurochem. 2010;115:297-313.

41. Royes LF, Fighera MR, Furian AF, et al. Neuromodulatory effect of creatine on extracellular action potentials in rat hippocampus: role of NMDA receptors. Neurochem Int. 2008;53:33-37.

42. Tachikawa M, Fujinawa J, Takahashi M, et al. Expression and possible role of creatine transporter in the brain and at the blood cerebrospinal fluid barrier as a transporting protein of guanidinoacetate, an endogenous convulsant. J Neurochem. 2008;107:768-778.

43. Stöckler S, Isbrandt D, Hanefeld F, Schmidt B, von Figura K. Guanidinoacetate methyltransferase deficiency: the first inborn error of creatine metabolism in man. Am J Hum Genet. 1996;58:914922.

44. Stöckler S, Schutz PW, Salomons GS. Cerebral creatine deficiency syndromes: clinical aspects, treatment and pathophysiology. Subcell Biochem. 2007;46:149-166.

45. Sullivan PG, Geiger JD, Mattson MP, Scheff SW. Dietary supplement creatine protects against traumatic brain injury. Ann Neurol. 2000;48:723-729.

46. Sakellaris G, Kotsiou M, Tamiolaki M, et al. Prevention of complications related to traumatic brain injury in children and adolescents with creatine administration: an open label randomized pilot study. J Trauma. 2006;61:322-329.

47. Sakellaris G, Nasis G, Kotsiou M, Tamiolaki M, Charissis G, Evangeliou A. Prevention of traumatic headache, dizziness and fatigue with creatine administration. A pilot study. Acta Paediatr. 2008;97:31-34.

48. Randolph C. Baseline neuropsychological testing in managing sport-related concussion: does it modify risk? Curr Sports Med Rep. 2011;10:21-26.

49. Mayers LB, Redick TS. Clinical utility of ImPACT assessment for postconcussion return-to-play counseling: psychometric issues. $J$ Clin Exp Neuropsychol. 2012;34:235-242.

50. Johnson B, Gay M, Zhang K, et al. The use of magnetic resonance spectroscopy in the subacute evaluation of athletes recovering from single and multiple mild traumatic brain injury. $J$ Neurotrauma. 2012;13:2297-2304. 